\title{
The Impact of Local Intervention Combined with Targeted Therapy on Metastatic Renal Cell Carcinoma
}

\author{
JIAN-RI LI ${ }^{1,2,3}$, YEN-CHUAN OU ${ }^{4}$, CHENG-KUANG YANG ${ }^{1}$, SHIAN-SHIANG WANG ${ }^{1,2,5}$, CHUAN-SU CHEN ${ }^{1,2}$, \\ HAO-CHUNG HO ${ }^{1}$, CHEN-LI CHENG ${ }^{1,2}$, CHI-REI YANG ${ }^{6}$, CHENG-CHE CHEN $^{1}$, SHU-CHI WANG ${ }^{1}$, \\ CHIA-YEN LIN ${ }^{1}$, SHENG-CHUN HUNG ${ }^{1}$, CHIANN-YI HSU ${ }^{7}$ and KUN-YUAN CHIU ${ }^{1,5}$ \\ ${ }^{1}$ Division of Urology, Department of Surgery, Taichung Veterans General Hospital, Taichung, Taiwan, R.O.C.; \\ ${ }^{2}$ Institute of Medicine, Chung Shan Medical University, Taichung, Taiwan, R.O.C.; \\ ${ }^{3}$ Department of Medicine and Nursing, Hung Kuang University, Taichung, Taiwan, R.O.C.; \\ ${ }^{4}$ Tung's Taichung Metro Harbor Hospital, Taichung, Taiwan, R.O.C.; \\ ${ }^{5}$ Department of Applied Chemistry, National Chi Nan University, Nantou, Taiwan, R.O.C.; \\ ${ }^{6}$ Department of Urology, China Medical University Hospital, Taichung, Taiwan, R.O.C.; \\ ${ }^{7}$ Department of Medical Research, Taichung Veterans General Hospital, Taichung, Taiwan, R.O.C.
}

\begin{abstract}
Background/Aim: We performed a retrospective survey on our metastatic renal cell carcinoma (MRCC) patients who had received targeted therapies, and afterwards evaluated the clinical impacts of local interventions on the patient outcomes. Materials and Methods: Between 2006 and 2016, 124 patients with MRCC who had received at least one line of tyrosine kinase inhibitors or mammalian target of rapamycin were included in the study. Seventy-five patients $(60.5 \%)$ received targeted therapies only, twenty-six patients received complete resection and the remaining 23 received incomplete local interventions for their metastatic lesions. Analysis of the basic characteristics, overall survival and multi-variant regression amongst the three groups was performed. Results: The age, gender distribution, tumor cell type, targeted therapy selection, line of therapies and sites of metastases were not different amongst the three groups. The targeted therapy-only group had a significantly higher percentage of Memorial Sloan Kettering Cancer Center (MSKCC) poor-risk patients compared with the other two groups $(22.7 \%$ vs. $3.8 \%$ and $0 \%, p=0.006$ respectively). The targeted treatment duration and follow-up duration was significantly shorted in the targeted therapy-only group. Of the twelve variables analyzed, complete resection and MSKCC poor-risk group showed a significant impact on the overall survival rate $(H R=0.5,95 \% C I=0.25-0.98, p=0.045$;
\end{abstract}

Correspondence to: Kun-Yuan Chiu, MD, Ph.D., 1650, Sec 4, Taiwan Blvd, Taichung 40700, Taiwan, R.O.C. Tel: +886 423592525, ext. 5120, e-mail: chiu3778@yahoo.com

Key Words: Local intervention, metastasectomy, metastatic renal cell carcinoma, targeted therapy.
$H R=2.97, \quad 95 \% C I=1.05-8.4, \quad p=0.04 \quad$ respectively). Conclusion: Complete resection of metastatic sites for MRCC patients, combined with targeted therapy, could provide better overall survival rates than targeted therapy alone. Poor MSKCC risk is still correlated to a poor outcome in the current targeted therapy era.

Prior to the development of targeted therapy, treatment of metastatic renal cell carcinoma (MRCC) was a dilemma. Although certain cases may have responded to immunotherapy, such as interleukin 2 or interferon alpha, amongst the majority of patients, surgery accounted for an important treatment option when providing local disease control and prolonging disease free survival in certain cases $(1,2)$. Since the new treatment paradigm of MRCC has already shifted towards molecular targeting, including tyrosine kinase inhibitors (TKIs), mammalian target of rapamycin inhibitors (mTORIs) and immune checkpoint inhibitors (ICIs), is there still a role for surgical intervention when treating these metastatic tumors (3-6)? Current data show diverse results on this issue (7). Karam et al. analyzed 22 patients who had received a metastasectomy after at least one line of systemic treatment. Eleven of them could achieve a disease-free status in a median duration of 43 weeks. The other 11 experienced disease recurrence after a median of 42 weeks (8). Brehmer et al. reported a median overall survival time of 67 months after local treatment for MRCC (9). You et al. evaluated $325 \mathrm{MRCC}$ patients and discovered that complete metastatic resection was correlated to both diseasefree survival and overall survival (10). Although these reports suggest that there are outcome benefits from a metastasectomy, what the optimal timing and applications are remain controversial. Not only there is a complicated 
patient selection bias, but variant disease factors including tumor cell type components, tumor growth rate and metastatic volumes may also influence treatment outcome. On the other hand, the recent success of the S-TRAC trial (Sunitinib as Adjuvant Treatment for Patients at High Risk of Recurrence of Renal Cell Carcinoma Following Nephrectomy) showed a high relapse rate of advanced highrisk renal cell carcinoma, where preventive TKIs therapy could prolong recurrence-free survival (11). This result can also be due to the systemic disease nature of MRCC, which plays a non-crucial role in focal MRCC treatments. Herein, we retrospectively collected our consecutive MRCC patients who had received targeted therapies alone or therapies combined with other metastatic site treatments (local interventions) and subsequently analyzed the patient outcomes.

\section{Materials and Methods}

Patients. This was a retrospective chart-review analysis of consecutive MRCC patients who had received at least one line of targeted therapy between 2006 and 2016. The review process was certified by the Institute Review Board of Taichung Veterans General Hospital, number CE13240A-2. Of the 131 consecutive patients, 7 were excluded due to incomplete data or loss of followup; with the remaining 124 patients being included in this analysis. Seventy-five patients $(60.5 \%)$ received targeted therapies only, twenty-six patients received complete resection, while the final 23 received incomplete local interventions for their metastatic lesions. The targeted prescription decisions were based upon the NCCN guidelines, the Taiwan Urologic Association kidney cancer treatment consensus and the public health insurance reimbursement policy in Taiwan. Patients who had received local interventions including surgical metastasectomy, cryotherapy, radiofrequency ablation or trans-arterial embolization over the course of their lifetime for treatment of MRCC were recorded.

Study assessment. All patients were primarily divided into three groups, targeted therapy only, complete resection, and incomplete local intervention. The definition of complete resection was "complete surgical removal of all targeted tumors with no other nontargeted lesions left remaining". All the other focal treatments or conditions not fit for the definition of complete disease control were defined as incomplete local intervention. Local metastatic control therapies included surgical metastasectomy, cryotherapy, radiofrequency therapy and trans-arterial embolization. The primary patient characteristics were gender, previous cytoreductive nephrectomy, cell type, Memorial Sloan Kettering Cancer Center (MSKCC) risk group, type of first line targeted therapy, survival status and the presence of metastatic site at the beginning of the study inclusion. The age, lines of targeted therapies, total treatment duration and follow-up duration were also compared between the two groups. In the subgroup analysis of the focal disease control group, parameters such as complete disease control, treatment procedures, lines of targeted therapies, total targeted treatment duration and follow-up duration were also analyzed. The overall survival comparison was performed according to the three subgroups. The intolerance of the study drugs with consequent drug shifting was recorded as the same line of therapy. The overall survival was defined as the period between the date of MRCC diagnosis and death of any cause. All regression variables were analyzed to differentiate their association with the patient's overall survival.

The differences amongst the three groups were analyzed using the Kruskal-Wallis test for continuous variables. The Chi-square test was used for categorical variables. The overall survival curves were plotted using the Kaplan-Meier method, with the statistical significance examined using the log-rank test. Pair comparison for overall survival between each of the two groups was also performed. Univariate and multivariate Cox hazard regression was used to estimate the hazard ratio (HR) and $95 \%$ confidence interval (CI) for correlations between variables and the overall survival. All statistical analyses were performed using SAS software version 9.2 (SAS Institute, Inc., Cary, NC, USA). A $p$-value of $<0.05$ was considered statistically significant.

\section{Results}

Table I demonstrates the basic characteristics of all MRCC patients. The age, gender distribution, clear-cell type percentage, percentage of TKIs used as the first line of therapy, total line of therapies, percentage of patient deaths and metastatic sites were not different amongst the three groups. The targeted therapy-only group displayed a significantly higher percentage of MSKCC poor-risk patients than those in the complete resection and incomplete local intervention groups $(22.7 \%, 3.8 \%$ and $0 \%$ respectively, $p=0.006$ ). The median targeted treatment duration was 6.9 months, while the median follow-up duration was 13.4 months in the targeted therapy-only group, which was significantly shorter than the other two groups (13.7 and 15.4 months, $p<0.001 ; 41.9$ and 41.3 months, $p<0.001$ respectively). The median overall survival estimate was 2.4 years for the targeted therapy-only group, 5.05 years for the complete resection group and 3.5 years for the incomplete local intervention group, which revealed a statistical difference amongst the three groups ( $p=0.024$, Figure 1). The median overall survival rate of the complete-resection group was shown to be significantly longer than the targeted therapy only group when using pair comparison $(p=0.015)$. Comparison between the complete-resection group and incomplete-intervention group, versus the incomplete-intervention group and targeted therapyonly group, showed no statistically significant difference ( $p=0.293$ and $p=0.106$ respectively). A univariate Cox regression test showed that complete resection and incomplete local intervention were positively associated with a better overall survival rate $(\mathrm{HR}=0.46,95 \% \mathrm{CI}=0.23-0.9, p=0.024$; $\mathrm{HR}=0.45,95 \% \mathrm{CI}=0.21-0.95, p=0.037$ respectively). The poor MSKCC-risk group was negatively associated with an overall survival rate $(\mathrm{HR}=3.96,95 \% \mathrm{CI}=1.42-11.03, p=0.008)$. However, in multivariate analysis, only complete resection $(\mathrm{HR}=0.5,95 \% \mathrm{CI}=0.25-0.98, p<0.045)$, and poor MSKCC-risk percentage $\quad(\mathrm{HR}=2.97,95 \% \mathrm{CI}=1.05-8.4, p=0.04)$ were associated with poor overall survival (Table II). 
Table I. Basic characteristics of all metastatic renal cell carcinoma patients.

\begin{tabular}{|c|c|c|c|c|c|}
\hline & $\begin{array}{c}\text { Total } \\
(\mathrm{n}=124)\end{array}$ & $\begin{array}{l}\text { Targeted therapy } \\
\text { only }(\mathrm{n}=75)\end{array}$ & $\begin{array}{c}\text { Complete } \\
(\mathrm{n}=26)\end{array}$ & $\begin{array}{l}\text { Incomplete } \\
\quad(n=23)\end{array}$ & $p$-Value \\
\hline Age & $57.0(58-66)$ & $58.0(59.5-68)$ & $59.5(56-65.3)$ & $56.0(0.6-62)$ & 0.552 \\
\hline Gender & & & & & 0.128 \\
\hline Female & $38(30.6 \%)$ & $26(34.7 \%)$ & $9(34.6 \%)$ & $3(13.0 \%)$ & \\
\hline Male & $86(69.4 \%)$ & $49(65.3 \%)$ & $17(65.4 \%)$ & $20(87.0 \%)$ & \\
\hline Cell type & & & & & 0.095 \\
\hline Others & $23(18.5 \%)$ & $18(24.0 \%)$ & $4(15.4 \%)$ & $1(4.3 \%)$ & \\
\hline Clear & $101(81.5 \%)$ & $57(76.0 \%)$ & $22(84.6 \%)$ & $22(95.7 \%)$ & \\
\hline MSKCC risk $\#$ & & & & & $0.006 * *$ \\
\hline F or I & $106(85.5 \%)$ & $58(77.3 \%)$ & $25(96.2 \%)$ & $23(100.0 \%)$ & \\
\hline $\mathrm{P}$ & $18(14.5 \%)$ & $17(22.7 \%)$ & $1(3.8 \%)$ & $0(0.0 \%)$ & \\
\hline First target drug & & & & & 0.772 \\
\hline TKIs\& & $108(87.1 \%)$ & $65(86.7 \%)$ & $22(84.6 \%)$ & $21(91.3 \%)$ & \\
\hline Others\& & $16(12.9 \%)$ & $10(13.3 \%)$ & $4(15.4 \%)$ & $2(8.7 \%)$ & \\
\hline Line of therapy & $2.0(1-2)$ & $2.0(1-2)$ & $2.0(1-2)$ & $2.0(1-2)$ & 0.639 \\
\hline Targeted treatment duration (Months) & $8.0(4.1-16.8)$ & $6.9(3.5-12)$ & $13.7(6.2-31.4)$ & $15.4(5.9-26.2)$ & $<0.001 * *$ \\
\hline Death & $70(56.5 \%)$ & $42(56.0 \%)$ & $14(53.8 \%)$ & $14(60.9 \%)$ & 0.878 \\
\hline Follow-up duration (Months) & $21.2(9.7-44.6)$ & $13.4(8.3-31.8)$ & $41.9(23.8-63.2)$ & $41.3(24.9-50.7)$ & $<0.001 * *$ \\
\hline Bone metastasis & $37(29.8 \%)$ & $24(32.0 \%)$ & $8(30.8 \%)$ & $5(21.7 \%)$ & 0.638 \\
\hline Lung metastasis & $79(63.7 \%)$ & $48(64.0 \%)$ & $14(53.8 \%)$ & $17(73.9 \%)$ & 0.344 \\
\hline Liver metastasis & $16(12.9 \%)$ & $10(13.3 \%)$ & $3(11.5 \%)$ & $3(13.0 \%)$ & 0.972 \\
\hline Lymph node metastasis & $38(30.6 \%)$ & $23(30.7 \%)$ & $8(30.8 \%)$ & $7(30.4 \%)$ & 1.000 \\
\hline Brain metastasis & $12(9.7 \%)$ & $7(9.3 \%)$ & $1(3.8 \%)$ & $4(17.4 \%)$ & 0.274 \\
\hline Soft tissue metastasis & $19(15.3 \%)$ & $13(17.3 \%)$ & $6(23.1 \%)$ & $0(0.0 \%)$ & 0.061 \\
\hline Metastatic sites $>1$ & $94(75.8 \%)$ & $68(90.7 \%)$ & $10(38.5 \%)$ & $16(69.6 \%)$ & $<0.001 * *$ \\
\hline
\end{tabular}

Chi-square test. Kruskal Wallis test. ${ }^{*} p<0.05,{ }^{*} p<0.01$. \#MSKCC: Memorial Sloan Kettering cancer risk group; F: favorable risk; I: intermediate risk; P: poor risk. ${ }^{\circledR}$ TKIs: Tyrosine kinase inhibitors included sunitinib, sorafenib, pazopanib; others included temsirolimus, everolimus and bevacizumab. Continuous data were expressed as median and IQR. Categorical data were expressed as numbers and percentages.

Of all local intervention patients, 34.7\% (17/49) involved synchronous metastases (Table III). Lungs were the most common sites for focal disease control procedures. Surgical resection $(91.8 \%, 45 / 49)$ was the most commonly performed procedure for local disease control. The median episode for the local disease control procedure was 1 (ranged from 1 to 10). Twenty-six percent (13/49) of patients received more than one procedure. A total of 87 procedures were performed, with lungs being the most common treatment site (36 procedures).

\section{Discussion}

Our results reveal that combining a complete resection of metastatic lesions with targeted therapy can prolong overall survival for MRCC patients, whereas the poor MSKCC risk group indicated a poor outcome.

Previously reported series have also supported the use of a metastasectomy, particularly for complete resection. You et al. were the first to compare the role of complete metastasectomy paired with targeted therapy only (10). They discovered that patients experienced better overall survival after complete resection, than those who underwent incomplete resection and targeted therapy only. In our series, the median overall survival rate was not different between the complete resection group and the incomplete local intervention group. A possible explanation for this was patient selection in the incomplete local intervention group. In their series, poor risk patients who were following IMDC criteria accounted for $37.9 \%$ of the group, which was far higher than the results in our series $(0 \%$ poor risk using MSKCC criteria). The selection bias may lead to a poorer outcome in their incomplete resection group, which could cause overall survival differences to appear.

Additionally, the targeted treatment duration was similar between our complete resection and incomplete intervention groups (Table I), with the median estimate overall survival being prolonged for 1.5 years in the complete resection group (Figure 1). We think this additional duration of overall survival was due to the value of complete resection in terms of it providing drug holidays to MRCC patients. The other evidence of this theory came from the detailed analysis of the complete resection group. Among the 26 patients who had complete tumor resection, only 5 of them could achieve a target therapy-free duration longer than 12 months after 

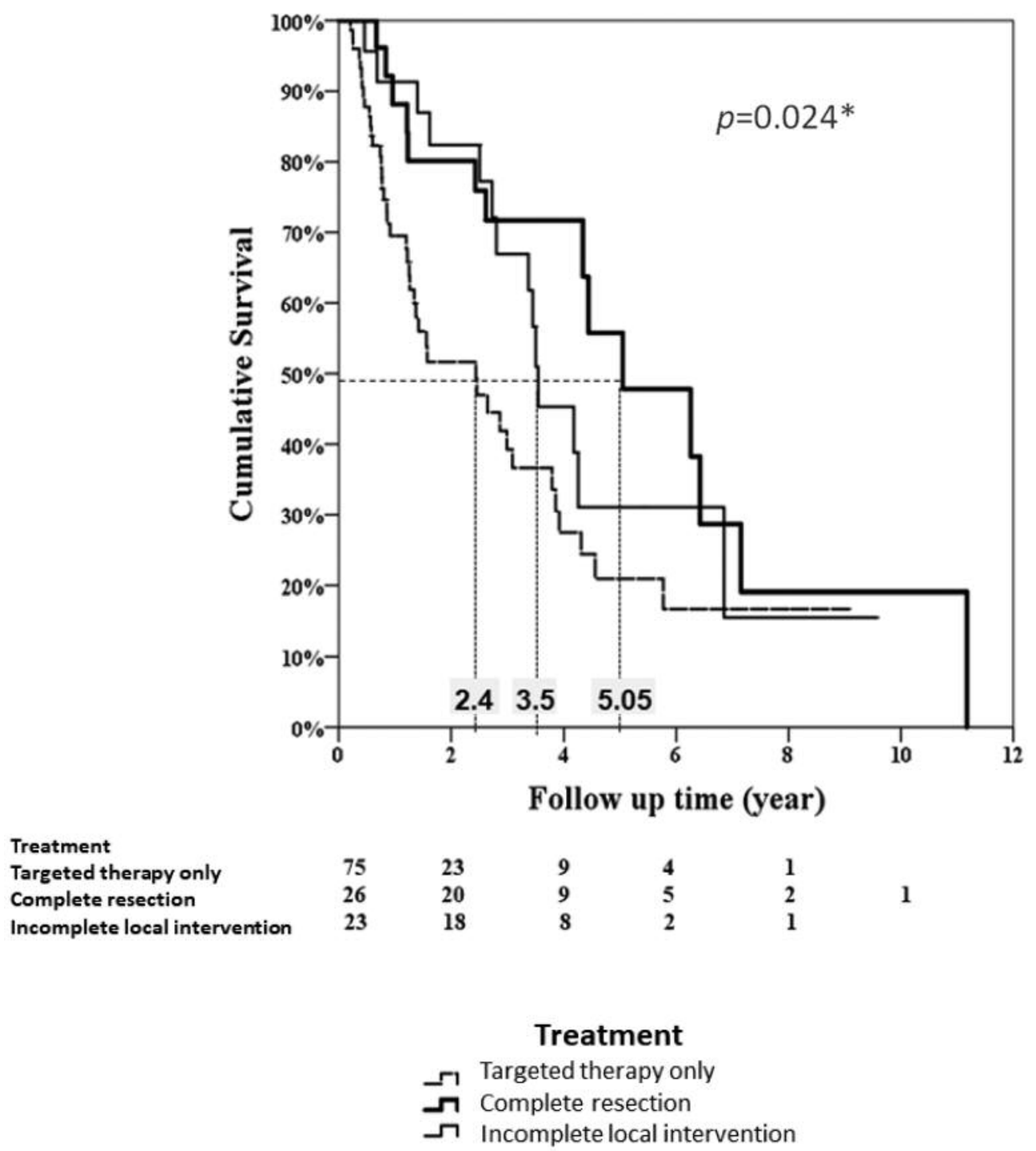

Figure 1. Overall survival comparison among the complete focal disease control group, incomplete focal disease control group and targeted therapyonly group.

their metastasectomy (Metastases to spine for 2 patients, lung for 1, adrenal gland for 1 and intra-peritoneal soft tissue for 1; median targeted therapy free survival time 29 months, ranging from 15 to 96 months). Among these 5 patients, 3 remained disease-free and 2 experienced newly metastatic lesions during follow-up. The remaining 21 patients who had complete resection experienced either newly metastatic lesions within one year (16 patients), or local recurrence (5 patients). The median targeted therapy free survival time was 6 months (range $=1-10$ months). Upon analysis of the subgroup data, we believe there are not only benefits to be had from drug holidays after local interventions, but also that there is an important role systemic targeted therapy plays in order to maintain long-term disease control. This is because of the high relapse rate.

There have been additional studies which have supported our findings. Karam et al. reported that their small series received a metastasectomy during targeted therapy (8). They found a median disease-free survival time of 43 weeks, and an overall survival benefit of longer than 2 years with a manageable complication rate (18\%, Grades 1 and 2$)$. Brehmer et al. also reported a similar experience when implementing pre-surgical targeted therapy followed by focal treatments (9). Both studies showed that a benefit of drug holidays after a metastasectomy is that patients could have a break from the adverse events of targeted therapies. 
Table II. Univariate and multivariate analysis for overall survival.

\begin{tabular}{|c|c|c|c|c|c|c|}
\hline & \multicolumn{3}{|c|}{ Univariate analysis } & \multicolumn{3}{|c|}{ Multivariate analysis } \\
\hline & HR & $(95 \% \mathrm{CI})$ & $p$-Value & HR & $(95 \% \mathrm{CI})$ & $p$-Value \\
\hline Age & 1.01 & $(0.98-1.04)$ & 0.482 & & & \\
\hline \multicolumn{7}{|l|}{ Local intervention } \\
\hline Targeted therapy only & & ref. & & & ref. & \\
\hline Complete & 0.46 & $(0.23-0.90)$ & $0.024 *$ & 0.50 & $(0.25-0.98)$ & $0.045^{*}$ \\
\hline Incomplete & 0.45 & $(0.21-0.95)$ & $0.037 *$ & 0.49 & $(0.23-1.05)$ & 0.066 \\
\hline \multicolumn{7}{|l|}{ Gender } \\
\hline Female & & ref. & & & & \\
\hline Male & 0.98 & $(0.53-1.81)$ & 0.950 & & & \\
\hline \multicolumn{7}{|l|}{ Cell type } \\
\hline Others & & ref. & & & & \\
\hline C lear & 0.91 & $(0.45-1.83)$ & 0.796 & & & \\
\hline \multicolumn{7}{|l|}{ MSKCC risk } \\
\hline F or I & & ref. & & & ref. & \\
\hline $\mathrm{P}$ & 3.96 & $(1.42-11.03)$ & $0.008 * *$ & 3.04 & $(1.07-8.63)$ & $0.037 *$ \\
\hline \multicolumn{7}{|l|}{ First target drug } \\
\hline TKIs & & ref. & & & & \\
\hline Others & 0.87 & $(0.39-1.96)$ & 0.737 & & & \\
\hline \multicolumn{7}{|l|}{ Bone metastasis } \\
\hline No & & ref. & & & & \\
\hline Yes & 0.95 & $(0.49-1.82)$ & 0.875 & & & \\
\hline \multicolumn{7}{|l|}{ Lung metastasis } \\
\hline No & & ref. & & & & \\
\hline Yes & 0.70 & $(0.40-1.22)$ & 0.206 & & & \\
\hline \multicolumn{7}{|l|}{ Liver metastasis } \\
\hline No & & ref. & & & & \\
\hline Yes & 0.56 & $(0.22-1.42)$ & 0.223 & & & \\
\hline \multicolumn{7}{|l|}{ Lymph node metastasis } \\
\hline No & & ref. & & & & \\
\hline Yes & 0.69 & $(0.35-1.34)$ & 0.273 & & & \\
\hline \multicolumn{7}{|l|}{ Brain metastasis } \\
\hline No & & ref. & & & & \\
\hline Yes & 0.19 & $(0.03-1.39)$ & 0.102 & & & \\
\hline \multicolumn{7}{|l|}{ Soft tissue metastasis } \\
\hline No & & ref. & & & & \\
\hline Yes & 1.29 & $(0.60-2.76)$ & 0.508 & & & \\
\hline \multicolumn{7}{|l|}{ Metastatic site $>1$} \\
\hline No & & ref & & & ref & \\
\hline Yes & 2.23 & $(1.13-4.38)$ & 0.020 & 1.73 & $(0.82-3.68)$ & 0.151 \\
\hline
\end{tabular}

Cox regression. ${ }^{*} p<0.05,{ }^{*} p<0.01$. MSKCC: Memorial Sloan Kettering Cancer Center.

Outcomes of different metastatic sites have been controversial (12-14). A study from the SEER (Surveillance, Epidemiology, and End Results) database shows that liver, bone, lymph nodes and brain metastases were associated with a poor outcome in the current targeted therapy era (12). Verma et al. retrospectively reviewed their single institute experience and revealed a median overall survival time of 6 months after the diagnosis of brain metastases from renal cell carcinoma (14). However, our results showed no statistical correlation between different metastatic sites and patient's overall survival (Table II). Jakubowski et al. and Kato et al. also reported their excellent experience with solid organ and spinal metastasectomies linked to high cancer specific survival ( $84 \%$ and $69 \%$ respectively), which could be achieved in both retrospective series $(15,16)$. However, both series attempted to control the enrolled cases in order to fit statistical comparison, thereby subsequently compromising the real world varieties of MRCC which showed high local recurrence and new metastases possibilities in our series.

The lungs were the most common site where a metastasectomy was performed in our series. This finding was similar to other series $(17,18)$. The most common 
Table III. Patients and local intervention characteristics.

\begin{tabular}{lc}
\hline & $\begin{array}{c}\text { Local intervention } \\
\text { patients } \mathrm{n}=49\end{array}$ \\
\hline Synchronous, n (\%) & $17(34.7 \%)$ \\
Local intervention sites & \\
Lung, n (\%) & $31(63.3 \%)$ \\
Liver, n (\%) & $5(10.2 \%)$ \\
Soft tissue (including intraperitoneal), n $(\%)$ & $16(32.7 \%)$ \\
Bone, n $(\%)$ & $13(26.5 \%)$ \\
Brain, n $(\%)$ & $5(10.2 \%)$ \\
Type of local intervention & \\
Resection, $\mathrm{n}(\%)$ & $45(91.8 \%)$ \\
TAE, n $(\%)$ & $4(8.2 \%)$ \\
Cryotherapy, n $(\%)$ & $5(10.2 \%)$ \\
RFA, n $(\%)$ & $2(4.1 \%)$ \\
Episodes of local intervention (Median/Range) & $1(1-10)$ \\
Patient of multiple procedures $(>1), \mathrm{n}(\%)$ & $13(26.5 \%)$ \\
\hline
\end{tabular}

metastasectomy procedure for lungs was a thoracoscopic wedge resection. Rather than undergoing a lung resection, one of our patients received cryotherapy over 10 sessions during a 2-year period. Clinically, detection of lung lesions can only be based upon a CT scan and intra-operative findings. The true complete resection is difficult to achieve.

Our retrospective study still had certain limitations. First, similarly to other studies, the retrospective selection bias may lead to a deviation of the results. In general, patients who received local interventions would have a good performance status as part of their MSKCC risk score. A poor MSKCCrisk group was correlated with a poorer outcome in our series. Second, the small patient numbers decreased the statistical power. Third, the decision of what type of local intervention to implement was not universal. Some patients received surgical resection while others received non-surgical local intervention. Fourth, although the targeted treatment durations were recorded, the true targeted drug dose intensities, along with variation between different regimens were still not identical. Since the targeted therapies were costly treatments, the different insurance reimbursement policy during different time points may also compromise the treatment options of individual patients in real world practice.

\section{Conclusion}

Our real-world patient data show that MRCC patients who received complete resection of metastatic sites combined with targeted therapy, can achieve better overall survival rates than those with targeted therapy alone. MRCC patients could benefit from drug holidays after a complete metastasectomy, which could in turn decrease adverse events from occurring during systemic treatments.

\section{Conflicts of Interest}

All Authors declare no conflicts of interest regarding this study.

\section{Acknowledgements}

The Authors would like to thank the Biostatistics Task Force of Taichung Veterans General Hospital for their assistance with the statistical analyses.

This research was supported by the Ministry of Science and Technology of the Republic of China, Grant number MOST 1052628-B-075A-001-MY3.

\section{References}

1 van der Poel HG, Roukema JA, Horenblas S, van Geel AN and Debruyne FM: Metastasectomy in renal cell carcinoma: A multicenter retrospective analysis. Eur Urol 35: 197-203, 1999.

2 Vogl UM, Zehetgruber H, Dominkus M, Hejna M, Zielinski CC, Haitel A and Schmidinger M: Prognostic factors in metastatic renal cell carcinoma: metastasectomy as independent prognostic variable. Br J Cancer 95: 691-698, 2006.

3 Li JR, Yang CK, Wang SS, Chen CS, Chiu KY, Cheng CL, Yang CR, Ho HC, Ko JL and Ou YC: First-line treatment result influence second-line regimen selection in targeted therapy for metastatic renal cell carcinoma. Anticancer Res 34: 5643-5647, 2014.

4 Motzer RJ, Escudier B, Oudard S, Hutson TE, Porta C, Bracarda S, Grünwald V, Thompson JA, Figlin RA, Hollaender N, Urbanowitz G, Berg WJ, Kay A, Lebwohl D and Ravaud A: Efficacy of everolimus in advanced renal cell carcinoma: a double-blind, randomised, placebo-controlled phase III trial. Lancet 372: 449-456, 2008.

5 Motzer RJ, Hutson TE, Cella D, Reeves J, Hawkins R, Guo J, Nathan P, Staehler M, de Souza P, Merchan JR, Boleti E, Fife K, Jin J, Jones R, Uemura H, De Giorgi U, Harmenberg U, Wang J, Sternberg CN, Deen K, McCann L, Hackshaw MD, Crescenzo R, Pandite LN and Choueiri TK: Pazopanib versus sunitinib in metastatic renal-cell carcinoma. N Engl J Med 369: 722-731, 2013.

6 Motzer RJ, Rini BI, McDermott DF, Redman BG, Kuzel TM, Harrison MR, Vaishampayan UN, Drabkin HA, George S, Logan TF, Margolin KA, Plimack ER, Lambert AM, Waxman IM and Hammers HJ: Nivolumab for metastatic renal cell carcinoma: Results of a randomized phase II trial. J Clin Oncol 33: 14301437, 2015.

7 Santoni M, Conti A, Partelli S, Porta C, Sternberg CN, Procopio G, Bracarda S, Basso U, De Giorgi U, Derosa L, Rizzo M, Ortega C, Massari F, Iacovelli R, Milella M, Di Lorenzo G, Buti S, Cerbone L, Burattini L, Montironi R, Santini D, Falconi M and Cascinu S: Surgical resection does not improve survival in patients with renal metastases to the pancreas in the era of tyrosine kinase inhibitors. Ann Surg Oncol 22: 2094-2100, 2015.

8 Karam JA, Rini BI, Varella L, Garcia JA, Dreicer R, Choueiri TK, Jonasch E, Matin SF, Campbell SC, Wood CG and Tannir NM: Metastasectomy after targeted therapy in patients with advanced renal cell carcinoma. J Urol 185: 439-444, 2011.

9 Brehmer B, Kauffmann C, Blank C, Heidenreich A and Bex A: Resection of metastasis and local recurrences of renal cell carcinoma after presurgical targeted therapy: probability of complete local control and outcome. World J Urol 34: 1061-1066, 2016. 
10 You D, Lee C, Jeong IG, Song C, Lee JL, Hong B, Hong JH, Ahn $\mathrm{H}$ and Kim CS: Impact of metastasectomy on prognosis in patients treated with targeted therapy for metastatic renal cell carcinoma. J Cancer Res Clin Oncol 142: 2331-2338, 2016.

11 Ravaud A, Motzer RJ, Pandha HS, George DJ, Pantuck AJ, Patel A, Chang YH, Escudier B, Donskov F, Magheli A, Carteni G, Laguerre B, Tomczak P, Breza J, Gerletti P, Lechuga M, Lin X, Martini JF, Ramaswamy K, Casey M, Staehler M, Patard JJ and Investigators ST: Adjuvant sunitinib in high-risk renal-cell carcinoma after nephrectomy. N Engl J Med 375: 2246-2254, 2016.

12 Abdel-Rahman O: Clinical correlates and prognostic value of different metastatic sites in metastatic renal cell carcinoma. Future Oncol, 2017. doi: 10.2217/fon-2017-0175. [Epub ahead of print]

13 Higuchi T, Yamamoto N, Hayashi K, Takeuchi A, Kato S, Miwa S, Abe K, Taniguchi Y, Aiba H and Tsuchiya H: The efficacy of wide resection for musculoskeletal metastatic lesions of renal cell carcinoma. Anticancer Res 38: 577-582, 2018.

14 Verma J, Jonasch E, Allen PK, Weinberg JS, Tannir N, Chang EL and Mahajan A: The impact of tyrosine kinase inhibitors on the multimodality treatment of brain metastases from renal cell carcinoma. Am J Clin Oncol 36: 620-624, 2013.
15 Jakubowski CD, Vertosick EA, Untch BR, Sjoberg D, Wei E, Palmer FL, Patel SG, Downey RJ, Strong VE and Russo P: Complete metastasectomy for renal cell carcinoma: Comparison of five solid organ sites. J Surg Oncol 114: 375-379, 2016.

16 Kato S, Murakami H, Demura S, Nambu K, Fujimaki Y, Yoshioka K, Kawahara N, Tomita K and Tsuchiya H: Spinal metastasectomy of renal cell carcinoma: A 16-year single center experience with a minimum 3-year follow-up. J Surg Oncol 113: 587-592, 2016.

17 Dabestani S, Marconi L, Hofmann F, Stewart F, Lam TBL, Canfield SE, Staehler M, Powles T, Ljungberg B and Bex A: Local treatments for metastases of renal cell carcinoma: a systematic review. Lancet Oncol 15: e549-e561, 2014.

18 Zaid HB, Parker WP, Safdar NS, Gershman B, Erwin PJ, Murad MH, Boorjian SA, Costello BA, Thompson RH and Leibovich BC: Outcomes following complete surgical metastasectomy for patients with metastatic renal cell carcinoma: A systematic review and meta-analysis. J Urol 197: 44-49, 2017.

Received June 21, 2018

Revised July 16, 2018

Accepted July 17, 2018 